\title{
EDUCAÇÃO INTEGRAL NO BRASIL
}

Isabela R. Leite*, Sabrina S. Valladão, Leticia D. Cortezia, Robson B. Sampaio (monitor), Prof. Dr. Josias Ferreira da Silva (monitor), Profa Dra. Débora C. Jeffrey (coordenadora).

\section{Resumo}

O presente trabalho teve como objetivo estudar a Educação Integral no Brasil, utilizando variadas metodologias com análise reflexiva-crítica e tendo como produto final a criação de um blog, para divulgar o trabalho realizado durante a pesquisa.

Palavras-chave:

Educação Integral, Tempo Integral, Blog.

\section{Introdução}

Esta pesquisa teve como objetivo estudar a Educação Integral no Brasil, sua historicidade, seu contexto sóciopolítico e legislações que envolvem a escola de Educação Integral no país.

Neste contexto de educação integral, a escola torna-se um espaço fundamental para assegurar aos estudantes uma formação integral, sociocultural, Interdisciplinar e multidisciplinar, de tal forma que possa inserir os alunos no processo de ensino e aprendizagem significativa e crítica.

Assim sendo, ao analisar a qualidade da educação básica no Brasil (jornada integral, educação integral ou escola em tempo integral), verificamos a partir de entrevistas com pesquisadores que estudam esta temática, das leituras e das pesquisas realizadas, uma melhor compreensão da realidade da escola em período integral no país.

\section{Resultados e Discussão}

Para analisar nosso objeto de pesquisa, utilizamos como referencial teórico o livro Educação Integral no Brasil: Inovações em Processo (GADOTTI, 2009), para compreender quais são os conceitos e as diferenças sobre Educação em Tempo Integral e Período Integral. Em seguida, realizamos uma análise reflexiva-crítica, por meio dialógico das pesquisas realizadas na Internet de palavras-chaves: educação integral, período integral, tempo integral, escola integral.

Nessa perspectiva, nosso entendimento a priori sobre o tema foi modificado pelas leituras e análise dos capítulos da bibliografia (GADOTTI, 2009) e das conversas dialógicas, reflexiva-crítica (FREIRE, 1996), bem como na participação no III Seminário do Grupo de Estudos e Pesquisas em Política e Avaliação Educacional (GEPALE) e do Encontro do Programa Nacional de Cooperação Acadêmica (Procad)/CAPES, promovido de 30 de Janeiro a 02 de Fevereiro de 2018, na Faculdade de Educação da Unicamp.

Para sistematizar com pesquisadores e com a sociedade como um todo, os conhecimentos obtidos durante esse período de vigência do PIBIC-EM, produzimos um Blog, com informações sobre a Educação Integral no Brasil, tendo a Internet como um espaço privilegiado para a socialização do resultado da pesquisa, além do XXVI Congresso de Iniciação Científica da Unicamp.
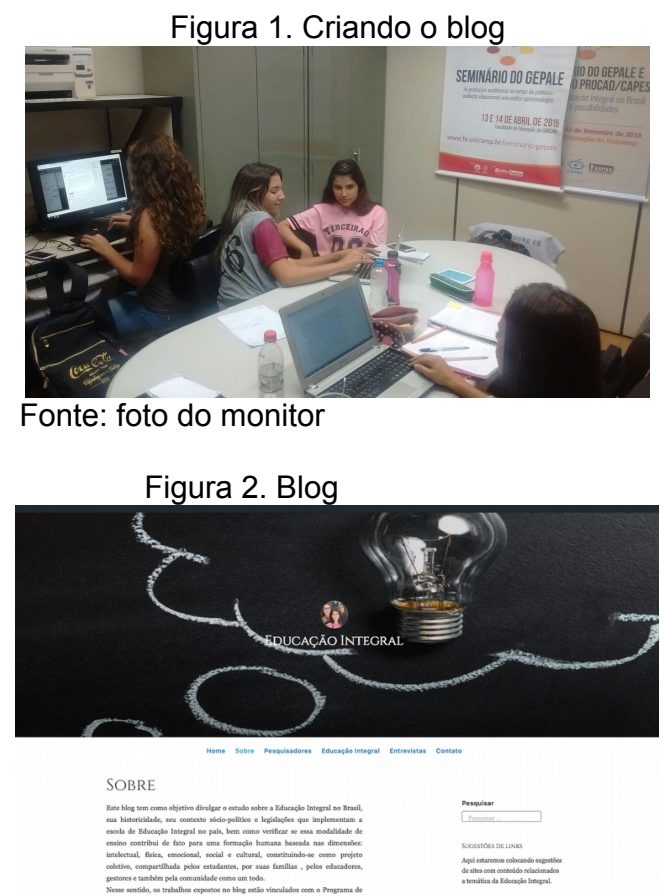

Fonte: Blog - https://goo.gl/CSTp7U

\section{Considerações Finais}

O estudo possibilitou a compreensão do panorama sobre a Educação Integral no Brasil. Também verificamos, através do material produzido, que existem limitações implicadas, pois percebemos uma complexidade para se implantar e implementar essa modalidade de educação no país, pela falta de formação continuada de docentes e a dificuldade de articulação e implantação de uma escola que atue de forma interdisciplinar, multidisciplinar e sócio-cultural, como eixo estruturante da Educação Integral .

\section{Referência}

GADOTTI, Moacir. Educação Integral no Brasil: Inovações em processo. São Paulo: IPF, 2009.

FREIRE, P. Pedagogia da autonomia: saberes necessários à prática educativa / Paulo Freire. - São Paulo: Paz e Terra, 1996. (Coleção leitura). 